\title{
CUTTING MECHANICS AND SURFACE FINISH FOR TURNING WITH DIFFERENTLY SHAPED CBN TOOLS
}

\begin{abstract}
In this paper, the basic cutting characteristics such as cutting forces, cutting power and its distribution, specific cutting energies were determined taking into account variable tool corner radius ranging from 400 to $1200 \mu \mathrm{m}$ and constant cutting parameters typical for hard turning of a hardened $41 \mathrm{Cr} 4$ alloy steel of $55 \pm 1 \mathrm{HRC}$ hardness. Finish turning operations were performed using chamfered CBN tools. Moreover, selected roughness profiles produced for different tool corner radius were compared and appropriate surface roughness parameters were measured. The measured values of $R a$ and $R z$ roughness parameters are compared with their theoretical values and relevant material distribution curves and bearing parameters are presented.
\end{abstract}

\section{Introduction}

Hard machining has been established an innovated machining technology for various highly-loaded machine components made of hardened steels, such as geared shafts, bearing and hydraulic components, which need a high quality surface finish and special functional properties [1-4]. Predominantly, scientific and engineering issues of hard turning cover such problems as cutting mechanics, chip formation, tool wear, surface integrity and part accuracy $[1,2]$. Unfortunately, surface finish in hard machining resulting from the specific action of the cutting edge with a high negative rake angle is still a great challenge and it is an important objective of hard machining research and practice. Moreover, it is a process with large energy consumption and low energy efficiency $[1,5]$ because the energy consumption increases distinctly due to extreme high hardness of the material machined and high negative rake angle of the $\mathrm{CBN}$ cutting tool used. In addition, the machined surface is evidently generated under severe influence of friction and excessive ploughing

\footnotetext{
${ }^{1}$ Opole University of Technology, Faculty of Mechanical Engineering, 45-271 Opole, P.O. Box 321, Poland.Email: k.zak@ po.opole.pl
} 
action of the cutting edge with the spring back effect. In addition, hard machining is distinguished by dominating passive force in comparison to conventional turning for which the radial force $F_{p}=(0.3-0.5) F_{c}$. Consequently, the radial force should be considered in static and dynamic behaviour of the machining system and total energy consumption. This specific issue becomes more important when machining with CBN cutting inserts of large nose radius of 800 and $1200 \mu \mathrm{m}$ [6]. As a result, for cutting tools with a corner radius equal to or higher than $1.2 \mathrm{~mm}$, uncut chip thickness decreases which intensifies ploughing forces [7, 8]. In this study, cutting forces, cutting power and energy consumption, surface finish were investigated under the variable tool nose radius and constant cutting speed in turning of $41 \mathrm{Cr} 5$ (AISI 5140) hardened steel.

In finish hard turning, the following values of cutting parameters are recommended when CBN cutting tools are used: the cutting speed $v_{c}=150 \div 300 \mathrm{~m} / \mathrm{min}$, feed rate $f=0.05 \div 0.2 \mathrm{~mm} / \mathrm{rev}$, depth of cut $a_{p}=0.05 \div 0.3 \mathrm{~mm}$ [9].

\section{Experimental details}

\subsection{Conditions of machining tests}

In this investigation, hard turning trials were performed using hardened $41 \mathrm{Cr} 4$ alloy steel with 55 \pm 1 HRC hardness and CBN cutting tool inserts of CB 7015 grade and TNGA configuration by Sandvik Coromant. The average cutting edge radius was equal to $r_{n}=10 \mu \mathrm{m}$ and the chamfer rake angle was $\gamma_{c f}=-30^{\circ}$. Three commercial cutting tool inserts with variable tool corner radius of $r_{\varepsilon}=400,800$ and $1200 \mu \mathrm{m}$ were used. Cutting parameters were constant and their values were kept at: cutting speed $v_{c}=210 \mathrm{~m} / \mathrm{min}$, feed rate $f=0.1 \mathrm{~mm} / \mathrm{rev}$ and depth of cut $a_{p}=0.2 \mathrm{~mm}$. Machining trials were performed on a three-axis CNC turning centre, Okuma Genos model L200E-M.

The constant values of cutting parameters were selected based on the recommendations of Sandvik Coromant, the producer of CBN inserts used. They were also used in previous author's studies [10,11]. The value of the feed rate of 0.1 $\mathrm{mm} / \mathrm{rev}$ is typical for FHT. It allows producing surfaces with $R a$ roughness parameters of about $1 \mu \mathrm{m}$. Moreover, this value of $R a$ parameter (in the range $0.63-1.25$ $\mu \mathrm{m}$ by technological recommendations) is required when dimensional accuracy satisfies IT6-7. The value of cutting speed of $210 \mathrm{~m} / \mathrm{min}$ was selected taking into account the compromise between tool life and productivity.

\subsection{Measurements of componential cutting forces and surface roughness}

Surface roughness produced on hardened steel specimens was measured by means of the stylus method using a TOPO-01P contact profilometer with a diamond stylus tip of $2 \pm 0.5 \mu \mathrm{m}$ radius. A set of $2 \mathrm{D}$ roughness parameters was determined and surface profiles were visualized using a Digital Surf, Mountains®Map package. 
Three components of the resultant cutting force $F_{c}, F_{f}$ and $F_{p}$ were measured using a three-component Kistler dynamometer (model 9129A) and consumed energy recording system installed on the lathe. The measured signals were processed with a sampling rate of $f=1 \mathrm{kHz}$ and a low-pass filter with a cut-off frequency of $f_{c}=300 \mathrm{~Hz}[7,8]$.

\subsection{Computations of specific cutting energies}

Specific cutting $e_{c}$ and ploughing $e_{p}$ energies are calculated based on the equivalent cutting edge of the length $l_{k}$ and the mean uncut thickness (UCT) shown in Fig. 1. The total specific cutting energy $\left(e_{t}\right)$ is the sum of its components $e_{c}$ and $e_{p}$ expressed by relevant Eqns. $1 \mathrm{a}$ and $1 \mathrm{~b}$. Hence

$$
\begin{aligned}
e_{c} & =\frac{F_{c}}{A_{c}} \\
e_{p} & =\frac{F_{p}}{A_{c}} \\
e_{t} & =e_{c}+e_{p}
\end{aligned}
$$

According to Fig. 1, the cross-sectional area of cut can be determined as follows:

$$
A_{c}=l_{k}+h_{m}
$$

where the equivalent length of cutting edge $l_{k}$ and average uncut chip thickness $h_{m}$ are:

$$
\begin{aligned}
l_{k} & =2 \kappa_{r e}+r_{\varepsilon} \\
h_{m} & =\frac{a_{p} f}{l_{k}}
\end{aligned}
$$

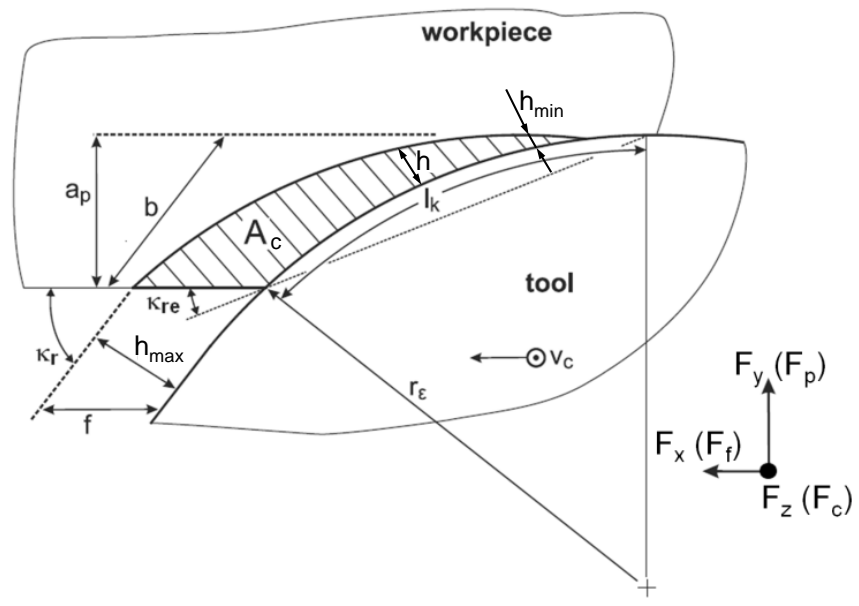

Fig. 1. Typical cross-section of the uncut chip layer for finish hard turning [8] 


\subsection{Computations of theoretical roughness parameters}

The theoretical values of roughness height $R z_{t}$ and average roughness $R a_{t}$ were determined using the classical circle model (Eq. 4a) and the corresponding model (Eq. 4b), respectively.

$$
\begin{aligned}
& R z_{t}=\frac{f^{2}}{8 r_{\varepsilon}} \\
& R a_{t}=\frac{f^{2}}{31.2 r_{\varepsilon}}
\end{aligned}
$$

\section{Experimental results and discussion}

\subsection{Cutting forces and cutting power}

As mentioned above, three components $F_{c}, F_{f}$ and $F_{p}$ of the resultant cutting force were recorded during hard turning passes using three cutting tool inserts with variable tool corner radius and the set of constant machining conditions using a piezoelectric dynamometer. Simultaneously, the cutting power $P_{c}$ was recorded along with other power components using a special measurement system [5]. The changes of three force components resulting from variations of the tool corner radius are presented in Fig. 2. As shown in Fig. 2, the minimum values of the cutting and passive forces were revealed for the minimum and maximum tool corner radii of 400 and $1200 \mu \mathrm{m}$, respectively. On the other hand, the minimum

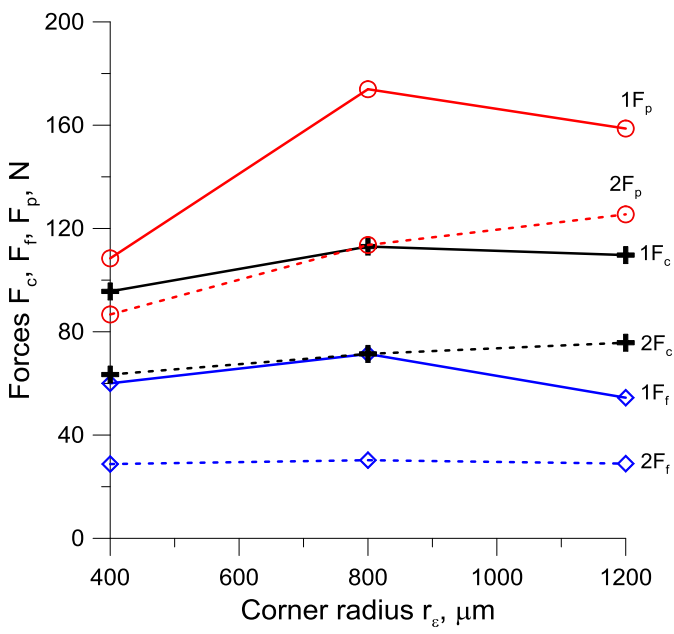

Fig. 2. Changes of $F_{c}, F_{f}$ and $F_{p}$ componential forces for variable tool nose radius. Cutting parameters: $1-v_{c}=210 \mathrm{~m} / \mathrm{min}, f=0.1 \mathrm{~mm} / \mathrm{rev}, a_{p}=0.2 \mathrm{~mm} ; 2-v_{c}=150 \mathrm{~m} / \mathrm{min}, f=0.1$ $\mathrm{mm} / \mathrm{rev}, a_{p}=0.1 \mathrm{~mm}[7]$ 
values of the feed force were recorded for the medium tool corner radius of 800 $\mu \mathrm{m}$ (Fig. 2). It should be noted that the values of passive force are distinctly higher than the corresponding values of cutting force $F_{c}$. The ratio of $F_{p} / F_{c}$ varies from 1.10 for lower tool corner radius of $r_{\varepsilon}=400 \mu \mathrm{m}$ to $1.45-1.55$ for higher values of $r_{\varepsilon}$. Its highest value was determined for $r_{\varepsilon}=800 \mu \mathrm{m}$ and the cutting speed of 210 $\mathrm{m} / \mathrm{min}$. This specific force resolution in hard machining causes the relevant changes in power consumption due to an intensive ploughing effect (abnormal value of the passive force $F_{p}$ ) and the generation mechanism of surface roughness.

The comparative data presented in Fig. 2 concern external cylindrical turning of a case-hardened $16 \mathrm{MnCrS5}$ (AISI 5115) steel with the average micro-hardness of 850-800 HV0.05 performed on a CNC lathe Gildemeister CTX 520 linear. CBN cutting tools, grade WBN 560 by CeramTec, with $56 \%$ CBN content and an average grain size of $3 \mu \mathrm{m}$ were used [7]. As shown in Fig. 2, the trends observed for all force components $F_{c}, F_{p}$ and $F_{f}$ are similar, but their literature values are lower due to lower value of the depth of cut $(0.1 \mathrm{~mm}$ versus $0.2 \mathrm{~mm}$ in own experimental study).

\subsection{Cutting energy balance}

The changes in the cutting power $P_{c}=F_{c} v_{c}$ recorded for different tool corner radii are shown in Fig. 3. The trends are similar to those observed for the cutting force $F_{c}$ (Fig. 2) when keeping constant cutting speed. In general, the difference between the calculated and measured values of the cutting power is not higher than $10 \%$. As shown in Fig. 3, its difference resulting from employing CBN tools with the tool corner radius of $r_{\varepsilon}=800$ and $1200 \mu \mathrm{m}$ is only about $2-5 \%$. This effect

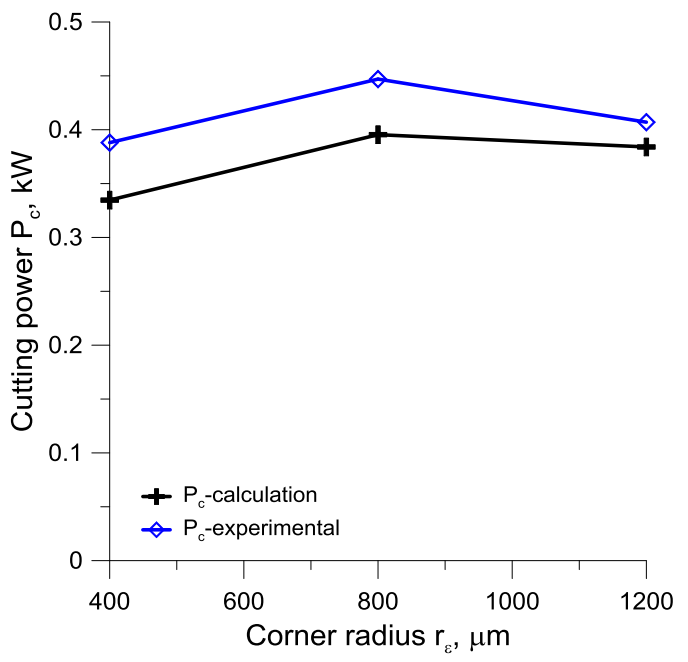

Fig. 3. Changes of cutting power for variable tool nose radius $\left(v_{c}=210 \mathrm{~m} / \mathrm{min}, f=0.1 \mathrm{~mm} / \mathrm{rev}\right.$,

$$
\left.a_{p}=0.2 \mathrm{~mm}\right)
$$


can be pronounced when considering the influence of the tool nose radius on the roughness height $R z_{t}$ (see Eqn. $4 \mathrm{a}$ ). The pie diagram presented in Fig. 4 indicates that in hard machining the power consumption strictly for cutting performance is about $14 \%$ of the total power recorded independently of the tool corner selected in this comparative studies.

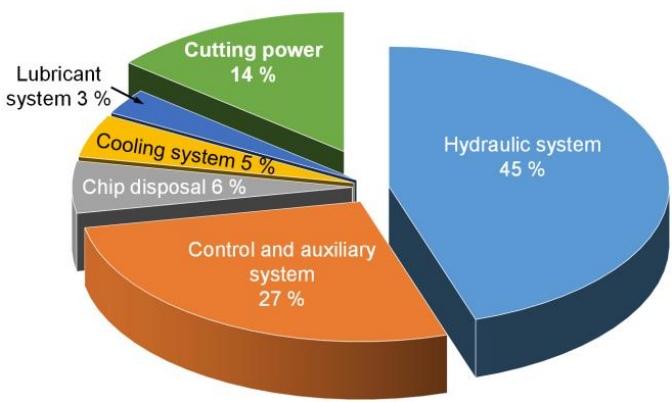

Fig. 4. Exemplarily distribution of cutting power recorded on a three-axis CNC lathe [5] ( $v_{c}=210$ $\left.\mathrm{m} / \mathrm{min}, f=0.1 \mathrm{~mm} / \mathrm{rev}, a_{p}=0.2 \mathrm{~mm}\right)$

The changes in the total specific energy $e_{t}$, the specific cutting energy $e_{c}$ and the specific ploughing energy $e_{p}$ are illustrated in Fig. 5. Fig. 5 shows that values of $e_{c}$ and $e_{p}$ components depend on the tool corner radius and varied in a similar way to the changes of relevant forces.

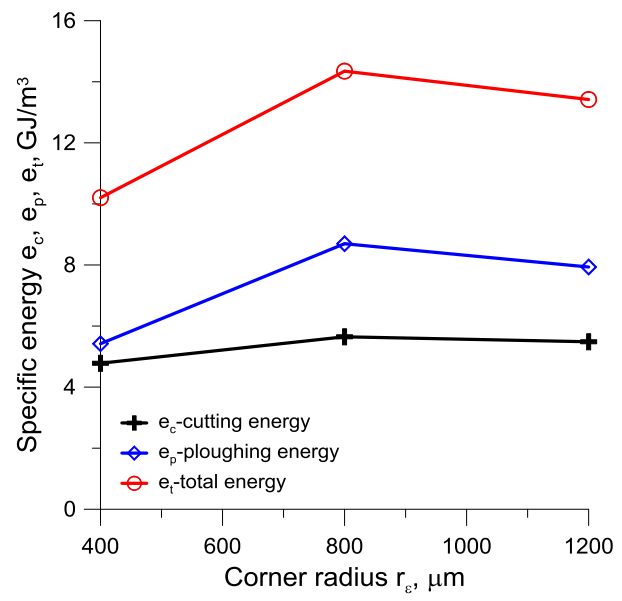

Fig. 5. Changes of $e_{c}, e_{p}$ and $e_{t}$ specific energies for variable tool corner radius $\left(v_{c}=210 \mathrm{~m} / \mathrm{min}\right.$, $f=0.1 \mathrm{~mm} / \mathrm{rev}, a_{p}=0.2 \mathrm{~mm}$ )

The minimum values of about $e_{c}=4.6 \div 4.9 \mathrm{GJ} / \mathrm{m}^{3}$ and $e_{p}=5.1 \div 5.9$ were recorded for the minimum tool corner radius of $400 \mu \mathrm{m}$. These values increased up to about $5.8 \mathrm{GJ} / \mathrm{m}^{3}$ for $e_{c}$ (on average by $20 \%$ ) and up to about $8.7 \mathrm{GJ} / \mathrm{m}^{3}$ for $e_{p}$ (on average by $35 \%$ ). As a result, the total specific energy is about $10 \mathrm{GJ} / \mathrm{m}^{3}$ for 
the tool corner radius of $400 \mu \mathrm{m}$ and about $15 \mathrm{GJ} / \mathrm{m}^{3}$ for the tool corner radius of 800 and $1200 \mu \mathrm{m}$. The cutting energy for lower tool corner radius is in the range characteristic for grinding with the uncut chip thickness (UCT) of about $15 \mu \mathrm{m}$ and for higher tool corner radius is in the range characteristic for conventional turning of carbon and alloy steels with the UCT higher than $20 \mu \mathrm{m}[2,8]$.

\subsection{Surface roughness}

Representative surface profiles generated by CBN tools with different tool nose radius and their zooms are shown in Fig. 6. It can be observed in Fig. 6 that the height of irregularities is substantially reduced due to employing higher tool corner. Another specific effect resulting from employing CBN tools with a large tool corner is a visible reduction of the RMS slope $R \Delta q$ from $4.37^{\circ}$ for $r_{\varepsilon}=400$ $\mu \mathrm{m}$ up to $1.64^{\circ}$ for $r_{\varepsilon}=1200 \mu \mathrm{m}$ (Fig. 6). Surface profiles presented in Fig. 6 consist of a series of regular feed marks but this effect is especially pronounced

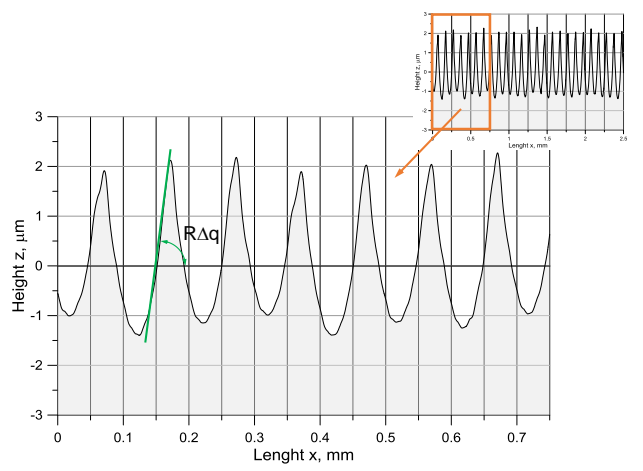

(a) $r_{\varepsilon}=400 \mu \mathrm{m}, R \Delta q_{0.4}=4.37^{\circ}$

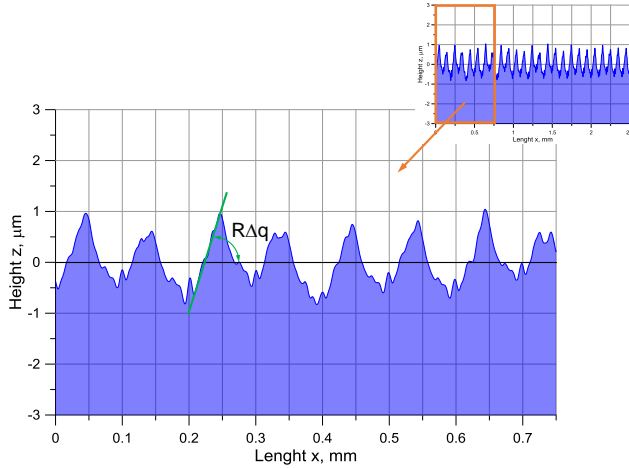

(b) $r_{\varepsilon}=800 \mu \mathrm{m}, R \Delta q_{0.8}=1.83^{\circ}$

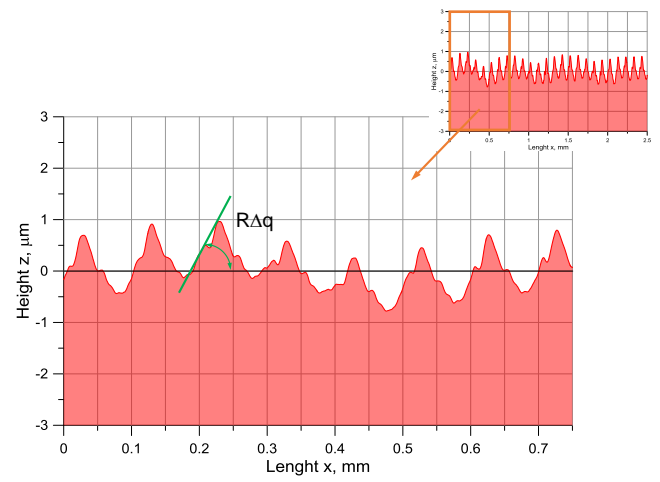

(c) $r_{\varepsilon}=1200 \mu \mathrm{m}, R \Delta q_{1.2}=1.64^{\circ}$

Fig. 6. Comparison of surface profiles generated by CBN tools with deferent tool corner radii for

$$
v_{c}=210 \mathrm{~m} / \mathrm{min}
$$


for the surface profile produced using CBN tool with the minimum $r_{\varepsilon}=400 \mu \mathrm{m}$. When the tool corner radius increases, feed marks are slightly distorted by small side flows observed on the left sides of all individual peaks. Their generation is resulting from the lateral plastic flow $[12,13]$ which occurs when the cutting edge removes a very thin layer of thermally softened material. It should be noticed that the average thickness of uncut layer decreases from 50 to about $30 \mu \mathrm{m}$ for the tool corner ranging from $r_{\varepsilon}=400$ to $1200 \mu \mathrm{m}$.

As shown in Fig. 7a, the maximum roughness height $R z$ decreases from 3.6 $\mu \mathrm{m}$ for $r_{\varepsilon}=400 \mu \mathrm{m}$, through 1.8 for $r_{\varepsilon}=800 \mu \mathrm{m}$ to $1.5 \mu \mathrm{m}$ for the highest $r_{\varepsilon}=1200 \mu \mathrm{m}$. As shown in Fig. 7a, the relevant values of the average roughness $R a$ are equal to $0.9,0.4$ and $0.3 \mu \mathrm{m}$. In addition, the real values of both $R a$ and $R z$ roughness parameters can be predicted with a reasonable accuracy using Eqns. $4 \mathrm{a}$ and $4 \mathrm{~b}$, but better prediction results concern the average roughness $R a$. This is due to fact that the predicted values of $R z$ parameter should be additionally corrected by appropriate elastic recovery of the machined surface (termed also springback) [14].

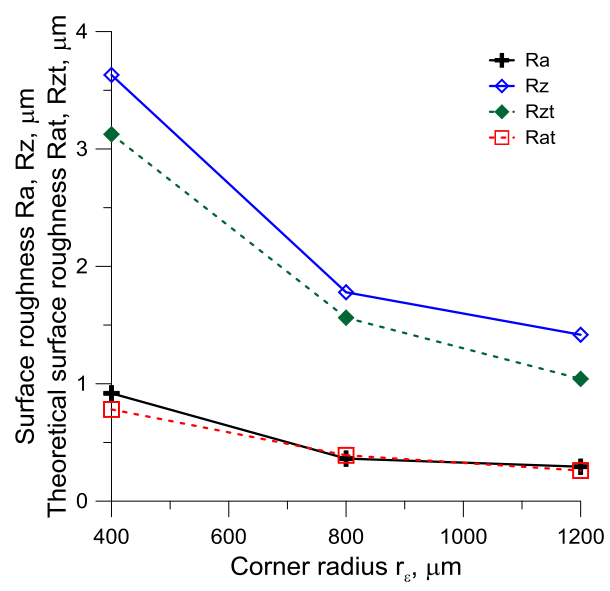

(a)

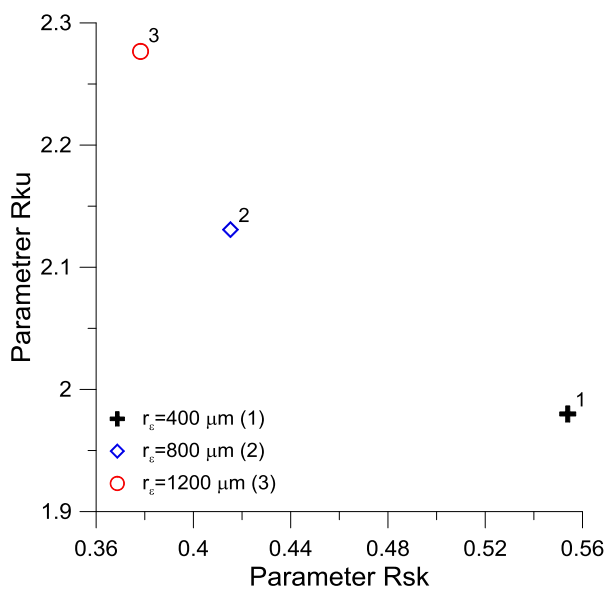

(b)

Fig. 7. Changes of $R a$ and $R z$ roughness parameters (a) and $R k u$ - $R s k$ envelope (b) for variable tool corner radius $\left(v_{c}=210 \mathrm{~m} / \mathrm{min}, f=0.1 \mathrm{~mm} / \mathrm{rev}, a_{p}=0.2 \mathrm{~mm}\right)$

Fig. 7b shows the relationship between kurtosis $(R k u)$ and skewness (Rsk) obtained for different tool corner radii. It should be noted in Fig. $7 \mathrm{~b}$ that the increase of tool corner radii causes that kurtosis increases slightly from about 2 to about 2.3 and the relevant values of $R s k$ parameter decrease from 0.55 to about 0.4 . In other words, such $R k u$-Rsk envelope is characteristic for surfaces with sharp irregularities which have better locking properties. In addition, kurtosis near 2 indicates that the profiles are congregated at the extremes.

Fig. 8 confirms that CBN hard turning produced surface profiles with unsatisfactory bearing properties but the increase of the tool corner ratio causes that 


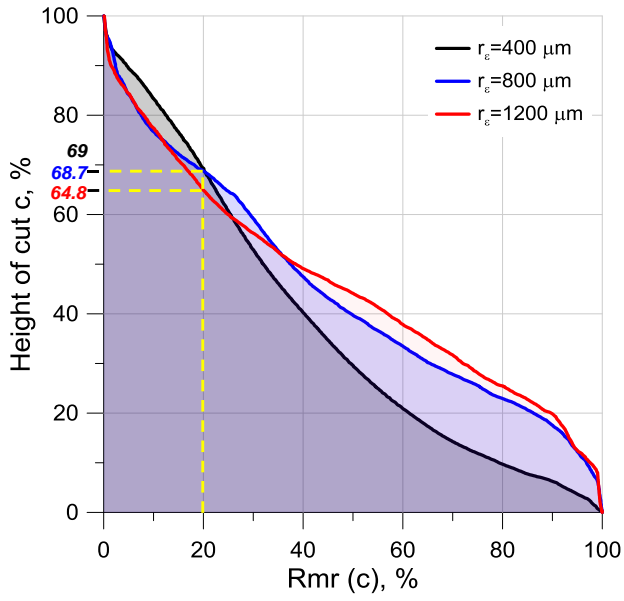

(a)

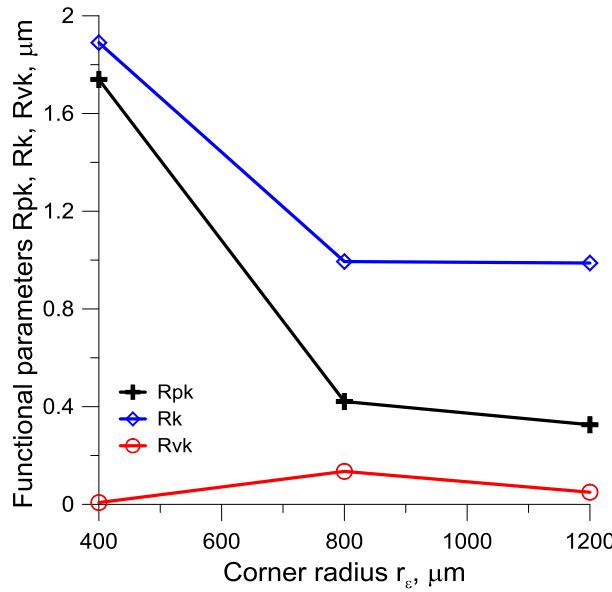

(b)

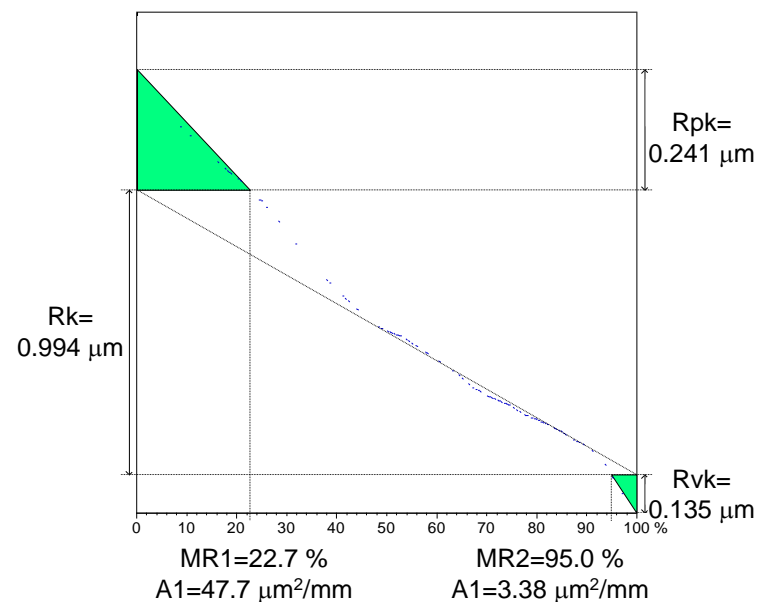

(c)

Fig. 8. Changes of material distribution curves (a) and bearing parameters for variable tool corner radius (b) and their visualization for constant tool corner radius (c) (constant cutting parameters: $\left.v_{c}=210 \mathrm{~m} / \mathrm{min}, f=0.1 \mathrm{~mm} / \mathrm{rev}, a_{p}=0.2 \mathrm{~mm}\right)$

the profiles of material ratio curve (MRC) changes from fully degressive for the minimum corner radius of $r_{\varepsilon}=400 \mu \mathrm{m}$ to progressive-degressive for higher tool corner radii of $r_{\varepsilon}=800$ and $1200 \mu \mathrm{m}$. The most important is that the increase of tool corner radii does not influence the material ratio at the cut above $70 \%$. This is in accordance with relevant changes of $R p k, R k$ and $R v k$ bearing parameters shown in Fig. 8b. In particular, The reduced peak height Rpk decreases markedly from $1.75 \mu \mathrm{m}$ to about $0.3 \mu \mathrm{m}$, whereas at the same time the reduced valley height $R v k$ increases from about $0.03 \mu \mathrm{m}$ to about $0.1 \mu \mathrm{m}$. Such substantial modification of 
peak heights in the surface profile suggests distinctly shorter running-time period during the surface's service. On the other hand, the reduced core height remains relatively high of about $1 \mu \mathrm{m}$.

\section{Conclusions}

1. The main observation in this study is that the tool corner radius ranging from 400 to $1200 \mu \mathrm{m}$ is a decisive geometrical factor which influences mechanical characteristics of the hard cutting process and control roughness of machined surfaces.

2. Its influence causes that the passive force $\left(F_{p}\right)$ overestimates both cutting $\left(F_{c}\right)$ and feed $\left(F_{f}\right)$ forces. Under the cutting conditions used, the ratio of $F_{p} / F_{c}$ is equal to 1.10 for tool corner radius of $400 \mu \mathrm{m}$ and increases to about 1.5 for higher values of $r_{\varepsilon}$.

3. The tool corner radius influences the specific cutting energy and the associated effect resulting from producing higher passive force is that that the comparable or higher amount of ploughing energy is dissipated. It was revealed, based on the experimental results obtained, that the specific cutting and ploughing energies increase on average by $20 \%$ and $35 \%$ when the tool corner radius increases from $400 \mu \mathrm{m}$ to $r_{\varepsilon}=800$ and $1200 \mu \mathrm{m}$.

4. Distinctly lower values of $R a$ and $R z$ roughness parameters were measured on hard surfaces machined using CBN chamfered cutting tools with higher tool corner radius applied. This effect corresponds to the theoretical formula (Eqn. 4a).

5. Due to producing regular (deterministic) surface profiles the measured values of real $R z$ and $R a$ roughness parameters differ not higher than about $\pm 10 \%$ from those predicted using theoretical formulas. At the tool nose radius equal or higher than $1200 \mu \mathrm{m}$, the profile regularity is distorted by flashes resulting plastic side flow effect.

Manuscript received by Editorial Board, February 09, 2017; final version, May 21, 2017.

\section{References}

[1] J.P. Davim. Machining of Hard Materials. Springer, London, 2011.

[2] W. Grzesik. Advanced Machining Processes of Metallic Materials. Elsevier Science, 2008.

[3] W. Grzesik. Prediction of the functional performance of machined components based on surface topography: State of the art. Journal of Materials Engineering and Performance, 25(10):44604468, 2016. doi: 10.1007/s11665-016-2293-Z.

[4] P. Nieslony, G.M. Krolczyk, K. Zak, R.W. Maruda, and S. Legutko. Comparative assessment of the mechanical and electromagnetic surfaces of explosively clad Ti-steel plates after drilling process. Precision Engineering, 47:104-110, Jan. 2017. doi: 10.1016/j.precisioneng.2016.07.011. 
[5] R. Chudy and W. Grzesik. Comparison of power and energy consumption for hard turning and burnishing operations of 41CR4 steel. Journal of Machine Engineering, 15, 2015.

[6] Y.K. Chou and H. Song. Tool nose radius effects on finish hard turning. Journal of Materials Processing Technology, 148(2):259-268, 2004. doi: 10.1016/j.jmatprotec.2003.10.029.

[7] R. Meyer, J. Köhler, and B. Denkena. Influence of the tool corner radius on the tool wear and process forces during hard turning. The International Journal of Advanced Manufacturing Technology, 58(9):933-940, 2012. doi: 10.1007/s00170-011-3451-y.

[8] W. Grzesik, B. Denkena, K. Żak, T. Grove, and B. Bergmann. Energy consumption characterization in precision hard machining using CBN cutting tools. The International Journal of Advanced Manufacturing Technology, 85(9):2839-2845, 2016. doi: 10.1007/s00170-0158091-1.

[9] Sandvik Coromant. Machining Handbook. www. sandvik.coromant.com.

[10] W. Grzesik and K. Żak. Producing high quality hardened parts using sequential hard turning and ball burnishing operations. Precision Engineering, 37(4):849-855, 2013. doi: 10.1016/j.precisioneng.2013.05.001.

[11] W. Grzesik, J. Rech, and K. Żak. Characterization of surface textures generated on hardened steel parts in high-precision machining operations. The International Journal of Advanced Manufacturing Technology, 78(9-12):2049-2056, 2015. doi: 10.1007/s00170-015-6800-4.

[12] H.A. Kishawy, A. Haglund, and M. Balazinski. Modelling of material side flow in hard turning. CIRP Annals - Manufacturing Technology, 55(1):85-88, 2006. doi: 10.1016/S00078506(07)60372-2.

[13] W. Grzesik. Generation and modelling of surface roughness in machining using geometrically defined cutting tools. In J.P. Davim, editor, Metal Cutting, chapter 6. Nova Science Publishers, New York, 2010.

[14] N. Schaal, F. Kuster, and K. Wegener. Springback in metal cutting with high cutting speeds. Procedia CIRP, 31:24-28, 2015. doi: 10.1016/j.procir.2015.03.065. 